$\widehat{\mathcal{G}}_{\text {https://doi.org/10.3765/sp.9.4 }}^{\text {Semantics \& Pragmatics Volume 9, Article 4: 1-23, } 2016}$

\title{
Comparing theories of quantifiers in than clauses: Lessons from downward-entailing differentials*
}

\author{
Nicholas Fleisher \\ University of Wisconsin-Milwaukee
}

Submitted 2015-03-06 / First decision 2015-04-27 / Revision received 2015-05-05 / Accepted 2015-05-12 / Early Access 2016-04-28 / Published 2017-12-21

\begin{abstract}
I investigate the effect of differential-phrase entailingness on the interpretation of comparative than clauses with quantificational subjects, a matter that has gone largely overlooked in the otherwise fecund recent literature. I show that only a subset of theories that derive the right readings for than clauses with quantifiers in the presence of an upward-entailing differential successfully generalize to cases with nonmonotone or downwardentailing differentials. The empirical paradigm presented here thus serves as an indispensable test suite for theories of comparatives and a useful probe for metatheoretical investigation. In particular, I show that theories in which the degrees associated with the than-clause-internal quantifier are not distributed over the matrix degree relation (ENCAPSULATION theories) fail to generate the right readings with downward-entailing differentials (and they generally require ad hoc tweaks in order to handle nonmonotone differentials). Theories in which those degrees are distributed over the matrix degree relation (ENTANGLEMENT theories) correctly derive the entire paradigm without further ado. I survey a number of recent theories of each type.
\end{abstract}

Keywords: comparatives, differentials, quantification, scope, entailingness

Post you to London, and you will find it so;

I speak no more than every one doth know

- Shakespeare, Richard II, act III, scene IV

\footnotetext{
* I thank Tue Trinh, Alexis Wellwood, the UWM S-Group audience, two anonymous reviewers, and associate editor Kjell Johan Sæbø for valuable feedback and discussion. The usual disclaimers apply.

(C)2016 Nicholas Fleisher

This is an open-access article distributed under the terms of a Creative Commons Attribution License (https://creativecommons.org/licenses/by/3.o/).
} 
Nicholas Fleisher

\section{Introduction}

Here I wish to focus on a class of data that has gone largely overlooked in the recent literature on comparative constructions but which has profound implications for the many theories and proposals advanced in that literature. The data of interest are comparative sentences that contain a downward-entailing (DE) differential phrase. Existing theories have been developed almost exclusively on the basis of examples with upward-entailing (UE) differentials (or with no overt differential at all, which amounts to the same thing entailingnesswise). As seen in (1) and (2), the entailingness of the differential makes an important difference in how the than clause is understood to be integrated into the rest of the sentence; in other words, there is an interpretive effect that goes beyond the lexical semantics of the differential itself.

(1) John is taller than every girl is.

(MAX reading)

(2) John is less than six inches taller than every girl is.

(MIN-\&-MAX reading)

The sentence in (1) is usually described as having a MAX reading: it is true just in case John's height is greater than that of the tallest girl. The sentence in (2), by contrast, has a stronger reading: it requires not merely that John's height be less than six inches greater than that of the tallest girl, but also that John's height be less than six inches greater than that of the shortest girl. I call this a MIN-\&-MAX reading. In (1) and other examples like it, the UE differential yields a fortuitous truth-conditional equivalence between the MAX and MIN-\&-MAX readings: if John is taller than the tallest girl, it follows that he is taller than the shortest girl. Many existing theories of comparatives, having been developed on the basis of examples with UE differentials, are consequently implemented so as to derive a logical form that yields the MAX reading in (1), with the MIN-\&-MAX reading following as an entailment. The existence of the truth-conditionally independent MIN-\&-MAX reading in examples like (2) has not been widely recognized, and consequently many theories have been developed without this crucial data point in mind. As I will show, only a subset of the theories that successfully derive the MAX reading in (1) also successfully derive the MIN-\&-MAX reading in (2). DE differentials thus serve as a useful probe for metatheoretical investigation, and examples containing them constitute a heretofore overlooked class of empirical data that all theories of comparatives must account for. 
In what follows, I examine several recent theories of quantifiers in than clauses and sort them into two broad classes. The crucial difference between the two classes is the way in which the than clause composes with the matrix clause. In theories of the first class, which I call ENCAPSULATION theories, the degrees associated with a than-clause-internal quantifier - that is, the degrees with which the quantified-over individuals are related, or to which they are mapped, by the relevant gradable adjective - are not distributed over the degree relation expressed in the matrix clause. The than clause is a semantically encapsulated unit that binds an argument position in the matrix clause, typically denoting either a single distinguished degree or an endpoint-containing scalar interval that has a distinguished degree as its lower bound. Representatives of this class of theories include Beck 2010 and Alrenga \& Kennedy 2014. In theories of the other class, which I call ENTANGLEMENT theories, the degrees associated with the thanclause-internal quantifier are distributed over the matrix degree relation (including the differential). Theories implement this variously via a meaning rule (Schwarzschild \& Wilkinson 2002, Landman 2009, 2010), syntactic scope taking at LF (Heim 2006), or plural predication (Beck 2013, 2014, Dotlačil \& Nouwen 2016). The result is that the comparative relation specified by the matrix degree operator and differential holds between the matrix subject's degree and each of the degrees associated with the quantified-over individuals in the than clause. As I show below, only entanglement theories are capable of deriving the correct truth conditions for comparative sentences across the full range of differential entailingnesses.

\section{Theoretical landscape and core data}

A major strand of the recent literature on comparatives has been devoted to the analysis of quantifiers in than clauses (see, e.g., Larson 1988, Gajewski 2008, Schwarzschild 2008, van Rooij 2008, Krasikova 2011, and works cited above). This has been a matter of some theoretical urgency ever since it came to the attention of researchers that maximality-based analyses of comparative clauses (in the mold of von Stechow 1984 and Rullmann 1995) systematically fail to generate the correct truth conditions for certain classes of examples. In particular, researchers have been at pains to provide a syntactically plausible derivation for clausal comparatives in which the than clause contains a quantificational element that appears to take matrix scope, as with the quantificational DP every girl in (1). 
The problem for maximality-based theories is by now familiar and can be summarized as follows: if (1) is true just in case John is taller than the maximal height that every girl has, this is equivalent to saying that John is taller than the shortest girl (since the maximal height $h$ such that every girl is at least $h$-tall is equal to the height of the shortest girl). This is a MIN reading. But (1) clearly has stronger truth conditions than that: it is true just in case John is taller than the tallest girl. In other words, it has a MAX reading, which is naturally paraphrased by giving the embedded universal subject syntactically exceptional matrix scope: for every girl $g$, John is taller than $g$ is.

Schwarzschild \& Wilkinson (2002) made a major advance in the attack on this problem. They developed a theory of quantifiers in than clauses that could derive the MAX reading for examples like (1) without doing violence to the syntax of scope taking. Moreover, they showed that apparent matrix scope readings are found with all manner of than-clause-internal scope-bearing elements, including those, like verbs and modals, that are not usually taken to be syntactically mobile. The solution to the problem of quantifiers in than clauses, then, could not reasonably be sought via principled tinkering with the clause-boundedness of QR. Instead, Schwarzschild \& Wilkinson proposed a fundamental alteration of the underlying semantics of gradable predicates and degree morphemes: an interval semantics.

At the heart of Schwarzschild \& Wilkinson's interval semantics is the proposal that gradable adjectives denote a relation between individuals and intervals of the relevant scale, rather than between individuals and degrees as on previous accounts. Abstraction in the than clause - effected by degree operator movement on most implementations - is thus abstraction over intervals rather than over degrees. As a result, than-clause-internal quantifiers over individuals play a compositional role in picking out properties of intervals rather than properties of degrees: for an example like (1), the semantics can deliver a set of intervals that contain every girl's height, rather than a set of degrees that lie below every girl's height. The individual quantifier thereby contributes to deriving the correct MAX reading without having to take scope outside the than clause. The dilemma for the syntax-semantics interface that bedeviled earlier accounts - the need to choose between getting the right truth conditions and obeying known restrictions on movement - is thus circumvented by the move to an interval semantics (setting aside certain scope ambiguities found with modals, on which see Heim 2006, Krasikova 2011, Alrenga \& Kennedy 2014). 
Most work since Schwarzschild \& Wilkinson 2002 has followed its pioneering lead and adopted an interval semantics or a functional equivalent. Implementations differ - sometimes intervals are baked directly into the lexical semantics of gradable adjectives (Schwarzschild \& Wilkinson 2002, Beck 2010), sometimes they are derived through the application of another functor (Heim 2006), and sometimes they are set aside in favor of degree quantifiers (Alrenga \& Kennedy 2014) or degree pluralities (Beck 2014, Dotlačil \& Nouwen 2016) that are meant to do similar work - but the basic idea has gained wide currency in the literature.

For all the recent efforts devoted to the analysis of quantifiers in than clauses, there has been relatively little attention paid to their unassuming (and often invisible) upstairs neighbors: matrix differential phrases. The recent literature has thus remained insufficiently alert to the way in which the readings found with than-clause-internal quantifiers depend on the semantics of the matrix differential. In particular, the entailingness of the differential has a systematic effect on the reading found with a given than-clause-internal quantifier, as shown in (3) for examples with than-clause-internal every.

(3) a. UE differential $\rightarrow$ MAX reading: John is (more than six inches) taller than every girl is.

b. DE differential $\rightarrow$ MIN-\&-MAX reading: John is less than six inches taller than every girl is.

c. Nonmonotone differential $\rightarrow$ MIN $=$ MAX reading: John is exactly six inches taller than every girl is.

UE and DE differentials give rise to MAX and MIN-\&-MAX readings, respectively, as described above. Nonmonotone differentials, as in (3c), give rise to a special case of the MIN-\&-MAX reading that I call the MIN=MAX reading. On this reading, we understand all the girls to be equal in height, since John is exactly six inches taller than both the tallest girl and the shortest girl.

The MIN=MAX reading found with nonmonotone differentials has recently caught the attention of some researchers (in particular the encapsulation theorists Beck and Alrenga \& Kennedy). Their work shows that encapsulation theories can sometimes be tweaked so as to derive the MIN=MAX reading found with nonmonotone differentials. The MIN-\&-MAX reading found with DE differentials, by contrast, has gone almost entirely unaddressed (with the notable exception of Landman 2009: 52). An important finding of the present paper is that the tweaks that allow encapsulation theories to handle nonmonotone differentials do not successfully generalize to DE differentials; 
such theories simply cannot derive the observed MIN-\&-MAX reading. The problems that non-UE differentials present for encapsulation theories are thus much more grave than has generally been appreciated.

I hasten to observe in this connection that there is every reason to believe that the syntactic structure of the than clause is invariant across the examples in (3). Theories of comparatives thus must be flexible enough to derive the pattern of readings seen in (3) under the assumption that the than clause itself contributes the same semantic information in all cases.

For reasons of space, I restrict my attention here to examples in which the than-clause-internal quantifier is a distributive universal headed by $\mathrm{ev}$ ery. Examples with existentials exhibit an analogous pattern of interpretive variation as a function of differential entailingness, but the availability of alternative means of deriving exceptional wide scope for existentials and indefinites makes possible a wider array of proposals to handle such data. I likewise set aside than-clause-internal modals.

\section{Encapsulation theories}

\subsection{Selection: Beck 2010}

The theory of Beck 2010 has two core components: a proposal that the than clause denotes a maximally informative set of degrees (often, but not always, a contiguous interval), and a selection mechanism for choosing from this set a single degree that serves as the standard of comparison. Unlike in many of the other theories we will examine, Beck eschews the use of covert scopal operators. As she puts it, "I want to come out of the calculation of the semantics of the than-clause holding in my hand the degree we will be comparing things to" (Beck 2010: 27; emphasis original), that is, a semantic object that can be plugged directly into a matrix degree function. Beck's theory is thus, in present terms, an encapsulation theory par excellence.

Beck treats gradable adjectives as denoting relations between individuals and sets of degrees; the set-of-degrees argument is abstracted over in the formation of the than clause (presumably via movement of a covert $\mathrm{A}^{\prime}$ operator, as is customary). Beck's lexical entry for tall and the LF and truth conditions for the than clause in the sentence John is taller than every girl is are shown in (4) and (5).

(4) $\llbracket$ tall $\rrbracket=\lambda D_{\langle d, t\rangle} \lambda x$.height $(x) \in D$

(Beck 2010: 28) 
Lessons from DE differentials

a. LF: wh $\lambda 1$ [every girl $\lambda 2$ [ $\mathrm{t}_{2}$ is $\mathrm{t}_{1}$-tall]]

b. Truth conditions: $\lambda D \cdot \forall x[\operatorname{girl}(x) \rightarrow \operatorname{height}(x) \in D]$

(Beck 2010: 31)

The very large set of intervals in (5b) is whittled down to a single degree via the selection mechanism, which is a two-step process. First, we apply a maximal informativity operator, $\mathrm{m}_{\text {inf }}$, defined in (6); for the example above, this yields the smallest interval that contains the heights of all the girls. ${ }^{1}$ Next, we apply a maximality operator, $\mathrm{Max}_{>}$, defined in (7); Max $>$delivers the greatest degree (or, more generally, the greatest degree in the highestextending interval) in the set yielded by $\mathrm{m}_{\text {inf }}$. In this way, the than clause delivers a single degree which can be fed into the semantic composition of the matrix clause, where Beck assumes the simple and straightforward degree-inequality semantics for the comparative operator shown in (8). For an example like (1), this strategy successfully yields a MAX reading, as sketched in (9).

$$
\begin{aligned}
& \mathrm{m}_{\text {inf }}\left(p_{\langle\langle d, t\rangle, t\rangle}\right) \\
& =\lambda D_{\langle d, t\rangle} \cdot p(D) \wedge \neg \exists D^{\prime}\left[p\left(D^{\prime}\right) \wedge D \neq D^{\prime} \wedge\left[p\left(D^{\prime}\right) \rightarrow p(D)\right]\right]
\end{aligned}
$$

(7) a. $\max _{>}:=$the max relative to the $>$relation on intervals or degrees

b. $\operatorname{Max}_{>}(p):=\max _{>}\left(\max _{>}(p)\right)$

the end point of the interval that extends furthest (Beck 2010: 31)

(8) $\llbracket-\mathrm{er} \rrbracket=\lambda d \lambda d^{\prime} . d^{\prime}>d$

(Beck 2010: 28)

(9) «John is taller than every girl is

$=1$ iff height $(\mathrm{J})>\operatorname{Max}_{>}\left(\mathrm{m}_{\text {inf }}(\lambda D . \forall x[\operatorname{girl}(x) \rightarrow \operatorname{height}(x) \in D])\right)$

$=1$ iff height $(\mathrm{J})>\operatorname{height}($ tallest girl $)$

Beck (2010: §3.4) recognizes the challenge that nonmonotone differentials present for her selection mechanism. In order to derive the MIN=MAX reading found in examples like (3c), Beck proposes to treat scalar intervals as consisting not of degrees but of subintervals constituting a cover: a set of contiguous, nonoverlapping subsets of the interval that collectively exhaust it and whose size is subject to contextual manipulation (Schwarzschild 1996). As Beck (2010: 56) writes, "the distinction between points and intervals dis-

1 I ignore intensionality here and have correspondingly simplified the definition found in Beck's (2010: 29) example 86a. The $\mathrm{m}_{\text {inf }}$ under discussion here is the special sets-of-degrees case of a more general $\mathrm{m}_{\text {inf }}$ function; see Beck 2010: 29 for discussion. 
solves under this view because what we usually call a point is an interval on the scale whose size depends on context."

The guiding intuition behind Beck's cover proposal is that, absent a suitably short than-clause interval, we might choose a cover whose elements are larger than the size of the differential, leading to what she calls a granularity clash. For example, if the girls' heights span a range of 24 inches, then we could select a cover with 3 -inch elements, rendering meaningless a proposition such as John is exactly two inches taller than every girl is, in which the differential specifies an amount smaller than the basic unit of measure picked out by the cover. Beck (2010: 59) suggests that the MIN=MAX reading is the outcome of a strategy adopted in order to avoid such clashes: "My suggestion is that if a potential granularity clash could only be avoided under an additional assumption of closeness, one tends to assume equality and a default Cover of the than-clause interval $D$ in terms of the singleton set $\{D\} . " 2$

Whatever the cover proposal's successes with nonmonotone differentials, it offers no principled way to derive the MIN-\&-MAX reading that we find with DE differentials. ${ }^{3}$ Beck's theory derives either a too-weak MAX reading or, if we default to a singleton cover as with nonmonotone differentials, a too-strong MIN=MAX reading. If we could constrain things such that the presence of a DE differential containing a modified numeral (e.g., less than six inches) triggered a default singleton cover of the than clause that was exactly the size of that numeral (six inches), then we could produce a MIN-\&-MAX reading essentially by stipulation. But it is not clear that we could avoid a granularity clash: it is hard to see how, with a DE differential, we could adhere to Beck's (2010: 57) requirement "that the cover of the relevant interval that the than-clause provides (via informativity) furnishes units that are smaller than the differential”, since a DE differential can be arbitrarily small.

2 One question for the cover proposal is why the MIN=MAX reading does not disappear in cases where the than-clause interval itself (and, perforce, the elements of any conceivable cover) cannot plausibly be larger than the differential: that is, where the threat of a granularity clash is removed. For example, in the sentence John is exactly 52 years older than every girl $i s$, we infer that the girls are equal in age, despite the fact that we know it to be implausible that the girls' ages (i.e., the than-clause interval) could span a range anywhere near as large as 52 years.

3 Beck (2010: 52) recognizes that DE differentials headed by at most give rise to a MIN-\&-MAX reading, or at least to a MIN reading (see her example 147), but does not return to such data in her subsequent discussion. 
In sum, Beck's proposal for dealing with nonmonotone differentials has problems of its own and fails to extend to examples with DE differentials. I suggest that this is not an accidental failure but a principled one: it stems from the encapsulating design of Beck's theory of than-clause interpretation, where the selection mechanism delivers a single than-clause degree to serve as an argument of the degree relation expressed by the matrix degree head. Absent some means of having the matrix degree relation hold of every relevant degree in the interval picked out by the than clause - the hallmark of entanglement theories - the theory will fail to account for the full differential entailingness paradigm.

\section{2 'No more’: Alrenga \& Kennedy 2014}

The theory of Alrenga \& Kennedy 2014 is the latest in a class of proposals dating back to Seuren 1973, all of which share the view that the core semantic ingredient of comparatives is the presence of a covert negative element in the than clause. The general strategy is to derive the proposition that there exists a degree $d$ such that the matrix subject has the gradable property in question to $d$ but its counterpart in the than clause does not. (For this reason, such theories are often called "A-not-A" theories.) I take Alrenga \& Kennedy's implementation to represent the state of the art in this line of theorizing (other recent exponents include Gajewski 2008, Schwarzschild 2008, and van Rooij 2008; for background on the family of proposals, see Beck 2010: §2.3 and Alrenga \& Kennedy 2014: §2). Though implemented quite differently from the theory of Beck (2010), Alrenga \& Kennedy's is likewise an encapsulation theory: the than clause serves as the argument of a higher operator (in this case, one denoted by than itself; see below for details), with the result that the degrees associated with the than-clause-internal quantifier are not distributed over the matrix degree relation. The theory thus fails to derive the variation in readings as a function of differential entailingness observed in (3).

Alrenga \& Kennedy's principal innovation is to introduce negation into the than clause not via covert sentential negation but via a covert negative degree quantifier, a silent version of the negative existential differential quantifier no. Alrenga \& Kennedy's lexical entry for their covert negative degree quantifier, NO, is shown in (10). Their LF and truth conditions for the than clause in John is taller than every girl is are shown in (11). 
a. LF: $\lambda 1$ [every girl $\lambda 3$ [NO $\lambda 2$ [ $\mathrm{t}_{3}$ is [ $\mathrm{t}_{2}\left[\left[\mathrm{MORE}\right.\right.$ tall] $\left.\left.\left.\left.\left.\mathrm{t}_{1}\right]\right]\right]\right]\right]$

b. Truth condition:

$$
\begin{aligned}
& \lambda d_{\text {stnd }} . \forall x\left[\operatorname{girl}(x) \rightarrow\left\{d_{\text {diff }} \mid \operatorname{height}(x) \geq d_{\text {stnd }}+d_{\text {diff }}\right\}=\emptyset\right] \\
& =\lambda d . \forall x[\operatorname{girl}(x) \rightarrow \operatorname{height}(x) \leq d] \\
& =\lambda d . \text { height }(\text { tallest girl }) \leq d
\end{aligned}
$$

Note that, on Alrenga \& Kennedy's assumptions, the adjective in the than clause is in the comparative degree, just like its main-clause counterpart, whence the occurrence of the degree morpheme MORE in (11). Silent NO originates in the differential argument position of this than-clause-internal comparative operator before moving to take scope. Alrenga \& Kennedy assume that individual quantifiers are barred from intervening between NO and its trace, invoking a version of the widely recognized but poorly understood Heim-Kennedy Constraint. ${ }^{4}$ For examples like the one at hand, this ensures that every scopes above NO, which in turn successfully derives the obligatoriness of the MAX reading here. ${ }^{5}$

With these assumptions in place, the than clause is constrained to denote the set of degrees $d$ such that every girl is no more than $d$-tall: this is the interval whose lower bound is the height of the tallest girl and whose upper bound is the scalar maximum. As we shall see below, the failure to keep track of any girl's height but the tallest constitutes a loss of information that will prove fatal once we turn to examples with DE differentials.

The semantic composition of (1) proceeds as sketched in (12)-(15). (Note that Alrenga \& Kennedy assume the presence of an existential degree quantifier sOME, defined in (13), binding the differential degree argument in the

4 The name "Heim-Kennedy Constraint" is due to Bhatt \& Pancheva (2004). The formulation adopted by Alrenga \& Kennedy (2014: 26) is as follows: "If the scope of a quantificational DP contains the trace of a DegP, it also contains that DegP itself."

5 As the reader can verify, an LF in which NO scopes above every yields a MIN reading. It bears emphasizing that the constraint barring NO > every in cases like (1) is purely syntactic in nature: as Alrenga \& Kennedy (2014: 27) show, silent No happily outscopes every when the latter occurs in object position, with the MIN reading indeed attested in such examples.

The situation is different with modals, which are not subject to the Heim-Kennedy Constraint. Indeed, a major strength of Alrenga \& Kennedy's proposal is its demonstration that the range of MIN and MAX readings found with modals inside than clauses very closely mirrors that found in matrix clauses with overt differential no. 
Lessons from DE differentials

matrix clause. We get the same truth conditions whether some outscopes the than clause or vice versa.)

(12) 【than $\rrbracket=\lambda P_{\langle d, t\rangle} \lambda Q_{\langle d, t\rangle} \cdot \exists d[P(d) \wedge Q(d)]$ (Alrenga \& Kennedy 2014: 15)

(13) $\llbracket$ SOME $\rrbracket=\lambda P_{\langle d, t\rangle} \cdot\{d \mid P(d)\} \neq \emptyset \quad$ (Alrenga \& Kennedy 2014: 17)

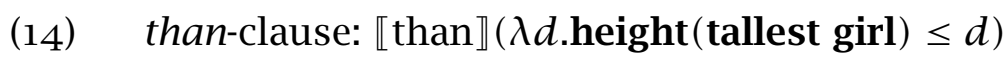

$=\lambda Q_{\langle d, t\rangle} \cdot \exists d[$ height$($ tallest girl $) \leq d \wedge Q(d)]$

(15) John is taller than every girl is.

a. LF: SOME $\lambda 2$ [[than clause] $\lambda 1$ [John is [ $\mathrm{t}_{2}$ [[MORE tall] $\left.\left.\left.\mathrm{t}_{1}\right]\right]\right]$

b. Truth conditions: True iff

$$
\begin{gathered}
\left\{d_{\text {diff }} \mid \exists d_{\text {stnd }}\left[\text { height }(\text { tallest girl }) \leq d_{\text {stnd }} \wedge\right.\right. \\
\text { height } \left.\left.(\mathbf{J}) \geq d_{\text {stnd }}+d_{\text {diff }}\right]\right\} \neq \emptyset \\
\text { i.e., iff } \exists d_{\text {stnd }}\left[\text { height }(\text { tallest girl }) \leq d_{\text {stnd }}<\operatorname{height}(\mathbf{J})\right]
\end{gathered}
$$

The LF in (15) yields the correct truth conditions: John is taller than every girl is just in case there is some degree of height $d$ such that John's height exceeds $d$ while the tallest girl's height is no greater than $d$.

In order to handle examples with nonmonotone differentials, Alrenga \& Kennedy invoke a variant of their silent NO operator that they call $\mathrm{NO}_{\max }$, defined in (16). Truth conditions for the sentence John is exactly six inches taller than every girl is are shown in (18). ${ }^{6}$

$$
\llbracket \mathrm{NO}_{\max } \rrbracket=\lambda P_{\langle d, t\rangle} \cdot \max (P)=0
$$

(Alrenga \& Kennedy 2014: 38)

(17) \exactly six inches $\rrbracket=\lambda P_{\langle d, t\rangle} \cdot \max (P)=6$ in $\quad$ (Alrenga \& Kennedy 2014: 37)

(18) «John is exactly six inches taller than every girl is

$$
\begin{array}{r}
=1 \text { iff } \max \left(\lambda d_{\text {diff }} \cdot \exists d_{\text {stnd }}[\forall x[\operatorname{girl}(x)\right. \\
\left.\left.\operatorname{height}(\mathbf{J}) \geq d_{\text {stnd }}+d_{\text {diff }}\right]\right)=6 \text { in }
\end{array}
$$

With $\mathrm{NO}_{\max }$, Alrenga \& Kennedy successfully derive the MIN=MAX reading in (18), which comes out true just in case the maximal degree that can be added to a value equal to all the girls' heights without exceeding John's height is exactly six inches.

The $\mathrm{NO}_{\max }$ solution, however, fails to extend successfully to examples with DE differentials, where we find a MIN-\&-MAX reading. Recall that, in the

6 With a nonmonotone differential and $\mathrm{NO}_{\max }$, we get the same truth conditions whether the differential outscopes the than clause or vice versa; see Alrenga \& Kennedy 2014: 39. 
presence of a DE differential, this reading is stronger than a MAX reading but weaker than a MIN=MAX reading. Alrenga \& Kennedy's system, as the reader can verify, delivers only the latter two readings: the MAX reading if we assume silent NO in the than clause, the MIN=MAX reading if we assume $\mathrm{NO}_{\max }{ }^{7}$

For all their differences in implementation, the theories of Beck (2010) and Alrenga \& Kennedy (2014) share an encapsulating design and a resultant inability to derive the full differential entailingness paradigm. Absent special interventions or tweaks, both theories derive MAX readings across the board when the than clause contains a universally quantified subject. Neither strategy for handling nonmonotone differentials succeeds with DE differentials. In order to derive the full paradigm we need a theory in which the matrix degree relation holds of each degree associated with an individual quantified over by the than-clause-internal quantifier, and this in turn requires not an encapsulating design but an entangling one.

\section{Entanglement theories}

\subsection{Internal theories: Schwarzschild \& Wilkinson 2002, Landman 2009, 2010}

While Schwarzschild \& Wilkinson (2002) were not the first to recognize the problem posed by quantifiers in than clauses - the observations date at least

7 For concreteness, assume that the DE differential less than six inches denotes the function $\lambda P_{\langle d, t\rangle}$. $\max (P)<6$ in. Once again, these are the readings we derive if the differential takes scope above the than clause. In this case, the different scope orders result in different readings. If less than six inches takes scope below existential than, we get the following truth conditions, which are far too weak: $\exists d_{\text {stnd }}\left[\right.$ height $($ tallest girl $) \leq d_{\text {stnd }} \wedge \max \left(\lambda d_{\text {diff }} \cdot \operatorname{height}(\mathrm{J}) \geq\right.$ $\left.d_{\text {stnd }}+d_{\text {diff }}\right)<6$ in]. This expression is true just in case there is some degree of height that is at or above the height of the tallest girl and to which we cannot add six inches without exceeding John's height. But we can find such a degree in any situation where John's height is greater than or equal to that of the tallest girl; in other words, the LF in which the DE differential scopes below than yields truth conditions for John is less than six inches taller than every girl is that are equivalent to the truth conditions for John is at least as tall as every girl is, clearly an unacceptable result. This LF must therefore be blocked; and indeed, Alrenga \& Kennedy make a similar observation about the interaction between existential than and matrix no. It should be noted, however, that whereas allowing existential than to scope above matrix differential no yields a tautology (Alrenga \& Kennedy 2014: 37), the offending configuration with less than six inches yields a contingent proposition. It is correspondingly more difficult to find a principled means of ruling out the latter LF. 
Lessons from DE differentials

to Larson $1988^{8}$ - their work did much to push it to the top of the theoretical agenda in the comparatives literature. Every other theory discussed here responds in some way to Schwarzschild \& Wilkinson's proposal. As discussed in section 2, their principal innovation was to cast the semantics of comparatives not in terms of degrees but in terms of scalar intervals, with the matrix and than clauses analyzed as predicates of such intervals. Crucial for our purposes is the fact that in their implementation, the matrix differential is interpreted "within" the than clause, that is, inside the definite interval description that must satisfy the interval predicate expressed by the than clause. Since the than-clause interval predicate, in turn, contains any than-clause-internal quantifiers that might occur, the interval property expressed by the differential must hold of all the degrees associated with the quantified-over individuals in the than clause. In other words, Schwarzschild \& Wilkinson's is an entanglement theory. This feature allows the theory to derive the full differential entailingness paradigm in a natural way.

Schwarzschild \& Wilkinson's semantics for comparatives is shown in (19):

$$
\operatorname{Mn}(\mu I[\operatorname{Sub}(\mu K[\operatorname{DIFF}(I-K)])])(\text { Schwarzschild \& Wilkinson 2002: 26) }
$$

$M n$ and $S u b$ are the interval predicates expressed by the main and subordinate (than) clauses, respectively; DIFF is the matrix differential, also a predicate of intervals; $I$ and $K$ are variables over intervals; and $\mu$ is a maximality operator, yielding the largest interval all of whose nonempty subintervals satisfy the property in its scope. ${ }^{9}$ On this implementation, then, the than clause denotes a predicate that is true of the largest interval all of whose nonempty subintervals are separated from each nonempty main-clause subinterval by the amount specified by the differential.

Schwarzschild \& Wilkinson attempt to remain syntactically agnostic, setting themselves the task of specifying the semantics that any particular

8 Larson developed an analysis in which the than clause denotes a generalized quantifier over individuals. As Larson himself realized, this system is not flexible enough to account for the full range of than-clause configurations (e.g., subcomparatives). Heim (2006), whose theory is discussed below, takes inspiration from Larson's proposal, but modifies things such that the than clause denotes a generalized quantifier over degrees.

9 Schwarzschild \& Wilkinson (2002: 23) define $\mu$ as in (i); the result is that " $\mu K^{\prime}[\phi]$ picks out the largest interval all of whose non-empty parts are $\phi . "$

(i) $\quad \mu K^{\prime}[\phi]=K$ iff $\forall K^{\prime}\left[\left(K^{\prime} \neq 0 \wedge K^{\prime} \subseteq K\right) \rightarrow \phi\left(K^{\prime}\right)\right] \wedge \forall K^{\prime \prime}\left[K \sqsubset K^{\prime \prime} \rightarrow\left(\exists K^{\prime}\left[K^{\prime} \sqsubset\right.\right.\right.$ $\left.\left.\left.K^{\prime \prime} \wedge \neg \phi\left(K^{\prime}\right)\right]\right)\right]$ 
syntactic implementation must derive. For expository purposes, I will adopt the following syntactic assumptions, all of which are based on suggestions of Schwarzschild \& Wilkinson (2002: 27): (i) the comparative degree operator -er denotes a function that takes the than-clause and differential denotations as arguments, as in (21); (ii) there is abstraction over intervals (and subsequent ellipsis) in the than clause, as in (22); and (iii) the matrix gradable predicate takes the complex of -er and its arguments as one argument and the matrix subject as another, as in (24). For an example like John is more than six inches taller than every girl is, this yields the following derivation.

$$
\llbracket \text { tall } \rrbracket=\lambda I \lambda x \text {.height }(x) \in I
$$

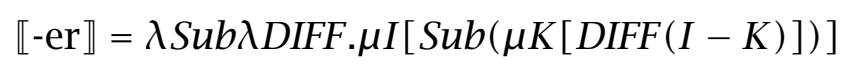

$$
\text { Sub }=\llbracket \text { than every girl is }\langle\text { tall }>\rrbracket=\lambda I . \forall x[\operatorname{girl}(x) \rightarrow \operatorname{height}(x) \in I]
$$

(23) $\quad D I F F=\llbracket$ more than six inches $\rrbracket=\lambda I .>6$ in $(I)$

(24) 【John is more than six inches taller than every girl is.』

$=\llbracket$ tall $\rrbracket(\llbracket-e r \rrbracket(S u b)(D I F F))(\mathrm{John})$

$=1$ iff height $(\mathrm{J}) \in \mu I[\forall x[\operatorname{girl}(x) \rightarrow \operatorname{height}(x) \in \mu K[>6 \operatorname{in}(I-K)]]]$

The truth conditions in (24) state that the sentence is true just in case John's height is contained in the largest interval $I$ all of whose nonempty subintervals are such that every girl's height is contained in the largest interval all of whose nonempty subintervals are more than six inches below $I$. Since John's height is in I and every girl's height is contained in an interval more than six inches below $I$, we derive a MAX reading, as desired with a UE differential: John is more than six inches taller than the tallest girl.

With the differential a part of the definite interval description that must satisfy the interval predicate denoted by the than clause, Schwarzschild \& Wilkinson's theory also derives the correct readings for examples with DE and nonmonotone differentials, as sketched for less than six inches in (25). (Schwarzschild \& Wilkinson do not discuss such examples; I owe this observation to an anonymous reviewer.)

(25) John is less than six inches taller than every girl is.

$\llbracket$ tall $\rrbracket(\llbracket$-er $\rrbracket(S u b)(\llbracket$ less than 6 in $\rrbracket))(J o h n)$

$=1$ iff height $(\mathrm{J}) \in \mu I[\forall x[\operatorname{girl}(x) \rightarrow \operatorname{height}(x) \in \mu K[<6 \operatorname{in}(I-K)]]]$

The crucial factor is that the interval maximality operator, $\mu$, requires that every nonempty subinterval of the interval in question satisfy the interval 
predicate in its scope. In (25), $\mu K[<6 i n(I-K)]$ picks out the largest interval all of whose nonempty subintervals are less than six inches below $I$. In order for every girl's height to fall within an interval all of whose nonempty subintervals are less than six inches below an interval $I$, both the tallest and the shortest girls' heights must be less than six inches below $I$; we thus derive a MIN-\&-MAX reading in (25). The same holds, mutatis mutandis, for a nonmonotone differential and MIN=MAX reading.

On the other end, the $\mu$ operator that applies to $I$ ensures that every nonempty subinterval of the interval containing John's height is within the distance from $K$ specified by the differential. This prevents these expressions from coming out true in scenarios where John's height is differentialfloutingly high up in an interval whose lowest point is the specified distance from the interval containing the girls' heights.

The ability of Schwarzschild \& Wilkinson's theory to derive the full differential entailingness paradigm stems from its entangling design: by interpreting the differential within the than clause, Schwarzschild \& Wilkinson ensure that the interval predicate denoted by the differential holds of the distance between the matrix subject's degree and each degree associated with the than-clause-internal quantifier (each girl's height, in the example above), not merely a single such degree (e.g., the greatest one).

That it is the entangling design of Schwarzschild \& Wilkinson's theory that is crucial for deriving the right result here, and not simply the move to an interval semantics, is evident from the work of Landman (2009, 2010), who develops a degree-based theory that he proves to be equivalent to Schwarzschild \& Wilkinson's interval-based theory. Landman's proposed semantics for clausal comparatives is sketched in (26), where $\alpha$ represents the matrix degree predicate (including the differential), $\delta$ is a degree-type variable, and $\mathrm{H}_{c m, w}$ is the relevant measure function.

$$
\llbracket \alpha \text { than }\left[\text { ср DP is }\left[{ }_{\text {PRED }}-\right]\right] \rrbracket=\lambda \delta \cdot \operatorname{DP}\left(\lambda y \cdot \alpha\left(\delta, \mathrm{H}_{c m, w}(y)\right)\right)
$$

Landman observes that the sine qua non of his theory is the fact that the matrix degree predicate $\alpha$ (which includes the differential) is interpreted internal to the than clause; hence he calls his theory the Internal Theory. The Internal Theory is, in present terms, an entanglement theory. ${ }^{10}$

10 I thank an anonymous reviewer for bringing Landman's work to my attention. Space precludes a fuller examination of Landman's proposal here. I refer the interested reader to his papers for details. 
Nicholas Fleisher

\subsection{Syntactic scope taking: Heim 2006}

Heim (2006) develops an entanglement theory on the model of Schwarzschild \& Wilkinson 2002. In Heim's theory, the degrees associated with the thanclause-internal quantifier are distributed over the matrix degree relation not via an "internalizing" lexical entry for comparative -er (cf. (21)), but rather via scope taking at LF. Specifically, Heim treats than clauses as generalized quantifiers over degrees that take scope via QR. Within the QR-ed than clause, an operator called $\Pi$ maps degree predicates into interval predicates within the scope of the quantificational DP subject. ${ }^{11}$ When the entire than clause raises to take scope, the result is widest scope for the than-clause-internal quantifier and a MAX reading for examples like (1).

Relevant details of the implementation are as follows. Gradable adjectives denote relations between individuals and degrees (not intervals), as shown in the lexical entry for tall in (27a). A phrasal constituent consisting of $\Pi$ and a wh-argument of type $\langle d, t\rangle$ moves from the degree-argument position of the than clause's gradable adjective for type reasons, binding the resulting type $d$ trace. The wh-argument of $\Pi$ subsequently moves to SpecCP within the than clause, inducing lambda abstraction over its trace. This yields the than-clause LF and truth conditions shown in (28). (My presentation closely follows that of Beck 2010: 12. $)^{12}$

(27) Lexical entries:

a. $\quad \llbracket$ tall $\rrbracket=\lambda d \lambda x$.height $(x) \geq d$

b. $\llbracket \Pi \rrbracket=\lambda D_{\langle d, t\rangle} \lambda P_{\langle d, t\rangle} \cdot \max (P) \in D$

(Heim 2006: 14)

(28) a. LF: $w h \lambda 1$ [every girl $\lambda 2\left[\left[\Pi \mathrm{t}_{1}\right] \lambda 3\left[\mathrm{t}_{2}\right.\right.$ is $\mathrm{t}_{3}$-tall]]]

b. Truth conditions: $\lambda D \cdot \forall x[\operatorname{girl}(x) \rightarrow \llbracket \Pi \rrbracket(D)(\lambda d$.height $(x) \geq d)]$

$=\lambda D . \forall x[\operatorname{girl}(x) \rightarrow \max (\lambda d$.height $(x) \geq d) \in D]$

$=\lambda D \cdot \forall x[\operatorname{girl}(x) \rightarrow \operatorname{height}(x) \in D]$

11 The name $\Pi$ is an abbreviation of "point to interval”. Heim (2006: 14) attributes the name and the basic proposal for the operator to Roger Schwarzschild in work presented at an MIT colloquium in 2004. The major impetus for the introduction of the scopally mobile $\Pi$ operator is to derive scope ambiguities found with certain than-clause-internal modals which Schwarzschild \& Wilkinson's theory cannot account for. Heim also discusses whether $\Pi$ might explain the distribution of negative polarity items in than clauses.

12 Like Alrenga \& Kennedy, Heim (2006: 15) must appeal to the Heim-Kennedy Constraint in order to rule out LFs in which an individual quantifier like every girl intervenes between $\Pi$ and its trace (though she derives scope ambiguities with than-clause-internal modals by allowing $\Pi$ to scope above or below them, much as Alrenga \& Kennedy do with NO). 
Lessons from DE differentials

Heim ignores the role of the matrix differential phrase, and so I have augmented her lexical entry for comparative -er with an additional degree argument; this is shown in (29). ${ }^{13}$ The than clause originates in the first degree argument position of -er (i.e., the position of the standard of comparison) before undergoing QR. The second degree argument of -er is occupied by the differential, which also moves for type reasons. The third and final degree argument of -er is left unsaturated; the resulting degree predicate serves as the argument of another, matrix-clause instance of $\Pi$.

With this much in place, we can derive the correct readings simply by letting the than clause scope over the differential: this yields a MAX reading with a UE differential, a MIN-\&-MAX reading with a DE differential, and a MIN=MAX reading with a nonmonotone differential. This is schematized in (31). ${ }^{14}$ (I set aside LFs in which the opposite scope order obtains. As pointed out by Beck (2010: 51ff.), these are potentially problematic; see footnote 15 for discussion.)

(29) $\llbracket$-er $\rrbracket=\lambda d \lambda d^{\prime} \lambda d^{\prime \prime} . d^{\prime \prime} \geq d+d^{\prime}$

(30) Matrix clause:

a. LF: [П [ $\mathrm{t}_{5}$ [-er than $\left.\left.\left.\mathrm{t}_{4}\right]\right]\right] \lambda 6$ [John is $\mathrm{t}_{6}$-tall]

b. Truth conditions: $\llbracket \Pi \rrbracket^{g}\left(\lambda d^{\prime \prime} \cdot d^{\prime \prime} \geq g(4)+g(5)\right)(\lambda d$.height $(\mathrm{J}) \geq d)$

$=1$ iff $\max (\lambda d$.height $(\mathrm{J}) \geq d) \in\left(\lambda d^{\prime \prime} . d^{\prime \prime} \geq g(4)+g(5)\right)$

$=1$ iff height $(\mathrm{J}) \geq \mathfrak{g}(4)+g(5)$

(31) John is DIFF taller than every girl is.

a. LF:

[than clause] $\lambda 4$ [DIFF $\lambda 5$ [[П [ $\mathrm{t}_{5}$ [-er than $\left.\left.\left.\mathrm{t}_{4}\right]\right]\right] \lambda 6$ [John is $\mathrm{t}_{6}$-tall]]]

b. Truth conditions:

$\llbracket$ than every girl is $\rrbracket\left(\lambda d_{\text {stnd }} \llbracket \llbracket \operatorname{DIFF} \rrbracket\left(\lambda d_{\text {diff }} \cdot \operatorname{height}(\mathbf{J}) \geq d_{\text {stnd }}+d_{\text {diff }}\right)\right)$

13 The standard of comparison in the comparative relation expressed by -er must now consist not solely of the standard argument, but of the concatenation of the standard and the differential; in this, I largely follow Alrenga \& Kennedy 2014. We must likewise assume that comparatives without an overt differential phrase contain default existential quantification over the differential argument, yielding truth conditions equivalent to those derived using Heim's semantics for -er (cf. the Alrenga \& Kennedy-style derivation in (15)).

14 Note that on Heim's assumptions, the lexical item than itself stays put; only its clausal complement undergoes QR. For ease of exposition and to facilitate comparison with other proposals, I persist in calling the constituent that moves the "than clause". Note further that the matrix П-phrase in (31a) must scope below both the differential and the than clause, lest their traces go unbound. 
Nicholas Fleisher

$$
\begin{aligned}
& =1 \text { iff } \forall x[\operatorname{girl}(x) \rightarrow \\
& \left.\quad \operatorname{height}(x) \in\left(\lambda d_{\text {stnd }} \llbracket \text { DIFF } \rrbracket\left(\lambda d_{\text {diff }} \cdot \operatorname{height}(\mathbf{J}) \geq d_{\text {stnd }}+d_{\text {diff }}\right)\right)\right] \\
& =1 \text { iff } \forall x\left[\operatorname{girl}(x) \rightarrow \llbracket \operatorname{DIFF} \rrbracket\left(\lambda d_{\text {diff }} \cdot \operatorname{height}(\mathbf{J}) \geq \operatorname{height}(x)+d_{\text {diff }}\right)\right]
\end{aligned}
$$

As (31) shows, entanglement is effected in Heim's theory by giving widest scope to the than clause, and thereby to the wide-scope individual quantifier within it. This ensures that each degree associated with a quantified-over individual satisfies the matrix degree relation (including the differential), the hallmark of entanglement theories.

A lingering worry about Heim's theory concerns its restrictiveness: for instance, allowing scopal interactions between $\Pi$ and modals within the than clause successfully predicts the possibility of ambiguity but overgenerates for many particular examples. The theory also lacks an explanation for the ungrammaticality of DE subjects in than clauses (on which see Beck 2010 and Dotlačil \& Nouwen 2016). ${ }^{15}$

15 The proponent of Heim's theory also must grapple with the range of derivable matrix-clause LFs, in particular with the fact that the than clause and the differential are clausemates and both take scope via QR. As Beck (2010: 51ff.) observes, when a nonmonotone differential takes scope above a than clause with a universal subject, we get an unattested MAX reading. The same is true when a DE differential takes scope above such a than clause, as the reader may verify.

Absent some principled means of ruling out the LFs in which the differential takes scope above the than clause, Heim's theory predicts thoroughgoing ambiguity for what are in fact unambiguous sentences. Is there some such principled means? One possibility is that these problematic LFs fall within the purview of the Heim-Kennedy Constraint, which rules them out. To be sure, from a syntactic standpoint both the than clause and the differential phrase are generalized quantifiers over degrees, binding traces of type $d$; we thus do not expect either one to count as an intervener for the other. Semantically, however, they have quite different effects: while the differential denotes a function that gives widest scope to a degree quantifier, the than clause, with the DP subject scoping above $\Pi$, denotes a function that gives widest scope to an individual quantifier. If this semantic effect is what underlies the prohibition on intervention embodied in the Heim-Kennedy Constraint, then the than clause should count as an intervener and be barred from taking scope between the differential and its trace. This then ensures that the LFs in which the than clause takes widest scope are the only ones permitted, and the predictions of spurious ambiguity detailed above are avoided. This suggestion, if it can be given a suitable formal characterization, reduces the problem of constraining matrix-clause scope taking within Heim's theory to the independently known problem of constraining than-clause-internal scope taking. I leave further investigation of this matter for future research. 
Lessons from DE differentials

\subsection{Plural predication: Beck 2014, Dotlačil \& Nouwen 2016}

A somewhat different approach to the problem of quantifiers in than clauses is developed by Beck (2014) (adapting her own earlier work on less comparatives in Beck 2013) and independently by Dotlačil \& Nouwen (2016). They propose to treat than clauses as denoting degree pluralities, with the than clause composing with the matrix clause (including the differential) via plural predication. Plural predication has the effect of quantifying universally over the atoms of the degree plurality expressed by the than clause: these form the restriction of the universal quantifier introduced by plural predication, with the matrix clause serving as its nuclear scope. Plural predication theories of comparatives are thus entanglement theories. Though implemented quite differently from the theories of Schwarzschild \& Wilkinson (2002) and Heim (2006), they too successfully derive the full differential entailingness paradigm due to their entangling design.

Dotlačil \& Nouwen (2016) explicitly discuss non-UE differentials and show how the plural predication approach handles them successfully. For reasons of space, I thus forgo a full exposition of this class of theories here. Instead, I will briefly discuss a few noteworthy features that distinguish the the plural predication approach from the other entanglement theories discussed above.

A feature that sets the plural predication approach squarely apart from the other entanglement theories is the mechanism for distributing the thanclause degrees over the matrix degree relation. Instead of having the thanclause-internal quantifier effect this distribution, as Schwarzschild \& Wilkinson, Landman, and Heim do, the plural predication approach achieves this via the syncategorematic plural predication rule itself. The rule is defined in (32); $P$ corresponds to the degree predicate denoted by the matrix clause, $D$ to the degree plurality denoted by the than clause.

$$
[* P](D)=1 \text { iff } \forall d \in D: P(d)=1
$$

(Beck 2014: 105)

On this implementation, then, the matrix degree relation (including the differential) is predicated of every than-clause degree. For Dotlačil \& Nouwen, the than-clause denotation is derived by abstracting over the degree plurality in the than-clause-internal quantifier's scope and then applying a maximal informativity operator to the result, returning a minimal degree plurality (for discussion, see Dotlačil \& Nouwen 2016: §7).

Dotlačil \& Nouwen observe that their theory successfully derives the infelicity of DE quantifiers in than-clause-internal subject position, maintaining 
the good predictions of Beck 2010 and setting both theories apart from Heim 2006, which overgenerates. They also suggest that the plural predication approach offers a natural analysis of cumulative readings in comparatives, which have not been widely discussed in the literature. I refer the interested reader to Dotlačil \& Nouwen's paper for details.

\section{Summary and outlook}

The foregoing survey of the recent literature on quantifiers in comparative than clauses has revealed two broad classes of theories: encapsulation theories and entanglement theories. By considering the interpretation of examples with DE matrix differential phrases - a crucial data point that has gone largely overlooked in the existing literature - I have argued that the correct theory of comparatives will be an entanglement theory. As we have seen, entanglement theories can be implemented in a number of different ways; space precludes a fuller consideration of the pros and cons of each implementation here. I hope to have shown that encapsulation theories, despite their often quite remarkable successes in handling than-clause-internal modals and other phenomena, are not up to the task of accounting for the systematic effect of differential entailingness on the interpretation of comparatives across the full monotonicity paradigm.

Numerous issues remain to be explored in future research. In considering DE differentials, I have focused here on examples headed by less, such as less than six inches. A fuller investigation would include other DE differentials, such as at most six inches and no more than six inches. As noted by Landman (2009: 52) and Beck (2010: 52), examples with at most seem to give rise to a MIN reading distinct from the MIN-\&-MAX reading found with less than, as shown in (33) and (34).

(33) John is less than six inches taller than every girl is.

(MIN-\&-MAX reading)

(34) John is at most six inches taller than every girl is. (MIN reading)

While the MIN reading available in (34) - as well as in the epigraph from Shakespeare, with no more - certainly offers no solace to encapsulation theories, I have not had space here to explore the robustness of this interpretive distinction, nor to compare the various entanglement theories' handling of the matter. 
Lessons from DE differentials

There is likewise much yet to be said about the range of readings found with than-clause-internal quantifiers other than distributive universals. For example, theories must be able to derive the general infelicity of comparatives with DE than-clause subjects while carving out a principled exception for class B modified numerals headed by at most, as shown in (35) (the class A/class B terminology is due to Nouwen 2010; for an account that treats the cardinality constraint on class B modified numerals as postsuppositional rather than at-issue, see Brasoveanu 2013). Even among UE subjects, the distinction in acceptability between class A and class B modified numerals as than-clause subjects, sketched in (36), remains an unresolved issue, as far as I am aware.

(35) a. \#John is taller than no girl is.

b. \#John is taller than fewer than four girls are. (class A fewer than)

c. John is taller than at most four girls are. (class B at most)

(36) a. ?John is taller than more than four girls are. (class A more than)

b. John is taller than at least four girls are. (class B at least)

It is my hope that the present study, in identifying a deep problem for one class of theories of than-clause interpretation, contributes to our theoretical common ground and thereby helps to narrow the range of options that can be brought to bear on the many open issues that remain.

\section{References}

Alrenga, Peter \& Christopher Kennedy. 2014. No more shall we part: Quantifiers in English comparatives. Natural Language Semantics 22(1). 1-53. https://doi.org/10.1007/s11050-013-9099-4.

Beck, Sigrid. 2010. Quantifiers in than-clauses. Semantics and Pragmatics 3(1). 1-72. https://doi.org/10.3765/sp.3.1.

Beck, Sigrid. 2013. Lucinda driving too fast again-The scalar properties of ambiguous than-clauses. Journal of Semantics 30(1). 1-63. https://doi.org/ 10.1093/jos/ffrol1.

Beck, Sigrid. 2014. Plural predication and quantified than-clauses. In Luka Crnič \& Uli Sauerland (eds.), The art and craft of semantics: A festschrift for Irene Heim, vol. 70, 91-115. Cambridge, MA: MIT Working Papers in Linguistics. http://semanticsarchive.net/Archive/jZiNmM4N/. 
Bhatt, Rajesh \& Roumyana Pancheva. 2004. Late merger of degree clauses. Linguistic Inquiry 35(1). 1-45. https://doi.org/10.1162/o02438904322793338. Brasoveanu, Adrian. 2013. Modified numerals as post-suppositions. Journal of Semantics 30(2). 155-209. https://doi.org/10.1093/jos/ffsoo3.

Dotlačil, Jakub \& Rick Nouwen. 2016. The comparative and degree pluralities. Natural Language Semantics 24(1). 45-78. https://doi.org/10.1007/s11050o15-9119-7.

Gajewski, Jon. 2008. More on quantifiers in comparative clauses. In Semantics and Linguistic Theory (SALT) 18, 340-357. Washington, DC: eLanguage. https://doi.org/10.3765/salt.v18io.2494.

Heim, Irene. 2006. Remarks on comparative clauses as generalized quantifiers. Ms., Massachusetts Institute of Technology. http://semanticsarchive. net/Archive/mJiMDBlN/.

Krasikova, Svetlana. 2011. Modals in comparatives. Universität Tübingen dissertation. https://publikationen.uni-tuebingen.de/xmlui/handle/109oo/ 46918.

Landman, Fred. 2009. Comparatives. Ms., Tel Aviv University. http://www. tau.ac.il/ landman/files/manuscripts /comparatives\%2ofall\%202009\% 2opart\%2oone.doc.

Landman, Fred. 2010. Internal and interval semantics for CP-comparatives. In Amsterdam colloquium 17, 133-142. Berlin: Springer. https://doi.org/ 10.1007/978-3-642-14287-1_14. http://www.tau.ac.il/ landman/Online_ papers/Pre_final/5.\%2oInternal\%2oand\%2ointerval\%2osemantics\%2ofor\% 20CP-comparatives.pdf.

Larson, Richard K. 1988. Scope and comparatives. Linguistics and Philosophy 11(1). 1-26. https://doi.org/10.1007/BFoo635755.

Nouwen, Rick. 2010. Two kinds of modified numerals. Semantics and Pragmatics 3(3). 1-41. https://doi.org/10.3765/sp.3.3.

van Rooij, Robert. 2008. Comparatives and quantifiers. In Olivier Bonami \& Patricia Cabredo Hofherr (eds.), Empirical issues in syntax and semantics 7 , 423-444. Paris: CSSP. http://www.cssp.cnrs.fr/eiss7/van-rooij-eiss7.pdf.

Rullmann, Hotze. 1995. Maximality in the semantics of WH-constructions. http: //lingserver.arts.ubc.ca/linguistics/sites/default/files/dissertation.pdf. University of Massachusetts, Amherst dissertation. http://scholarworks. umass.edu/dissertations/AAI9524743.

Schwarzschild, Roger. 1996. Pluralities. Dordrecht: Kluwer. https://doi.org/ 10.1007/978-94-017-2704-4. 
Lessons from DE differentials

Schwarzschild, Roger. 2008. The semantics of comparatives and other degree constructions. Language and Linguistics Compass 2(2). 308-331. https: //doi.org/10.1111/j.1749-818X.2007.00049.X.

Schwarzschild, Roger \& Karina Wilkinson. 2002. Quantifiers in comparatives: A semantics of degree based on intervals. Natural Language Semantics 1O(1). 1-41. https://doi.org/10.1023/A:1015545424775.

Seuren, Pieter A. M. 1973. The comparative. In Ferenc Kiefer \& Nicolas Ruwet (eds.), Generative grammar in Europe, 528-564. Dordrecht: Reidel. https: //doi.org/10.1007/978-94-010-2503-4_22.

von Stechow, Arnim. 1984. Comparing semantic theories of comparison. Journal of Semantics 3(1-2). 1-77. https://doi.org/10.1093/jos/3.1-2.1.

Nicholas Fleisher

Department of Linguistics

University of Wisconsin-Milwaukee

P.O. Box 413

Milwaukee, WI 53201-0413

fleishen@uwm.edu 